\title{
A recombination hotspot responsible for two inherited peripheral neuropathies is located near a mariner transposon-like element
}

Lawrence T. Reiter, Tatsufumi Murakami, Thearith Koeuth, Liu Pentao, Donna M. Muzny, Richard A. Gibbs \& James R. Lupski

Nature Genet. 12, 288-297 (1996).

The size of the EcoRI/SacI/NsiI HNPP deletion junction fragment reported in our manuscript is actually $7.3 \mathrm{~kb}$, not $7.8 \mathrm{~kb}$, due to the presence of an NsiI site located outside of the hotspot region in both CMT1A-REPs which changes the size of this fragment. The sizes of the CMT1A duplication junction fragments and the region of exchange in both duplication and deletion patients are unaffected by this size discrepancy.

Figure: This Southern blot containsEcoRl + Sacl digested (E/S) or EcoRl +Sacl +Nsil digested (E/S/N) DNA from YACs spanning the proximal and distal CMT1A-REPs (yc49H7 and yc225A3), genomic DNA from HNPP deletion patients (BAB944 and BAB957), genomic DNA from CMT1A duplication patients (BAB603 and BAB681) and genomic DNA from an unaffected control individual. The blot was hybridized with the $6.0-\mathrm{kb}$ insert from plasmid $\mathrm{pLR} 6.0$ which originates from the distal CMTIA-REP and spans the recombination hotspot previously described. Arrows indicate the locations of HNPP deletion and CMT1A duplication junction fragments. Note that the 7.8-kb HNPP deletion junction fragments change to $7.3 \mathrm{~kb}$ in the triple digest while the sizes for the CMT1A duplication fragments remain as previously reported (3.2 kb for $\mathrm{E} / \mathrm{S}$ and $1.7 \mathrm{~kb}$ for $\mathrm{E} / \mathrm{S} / \mathrm{N})$.

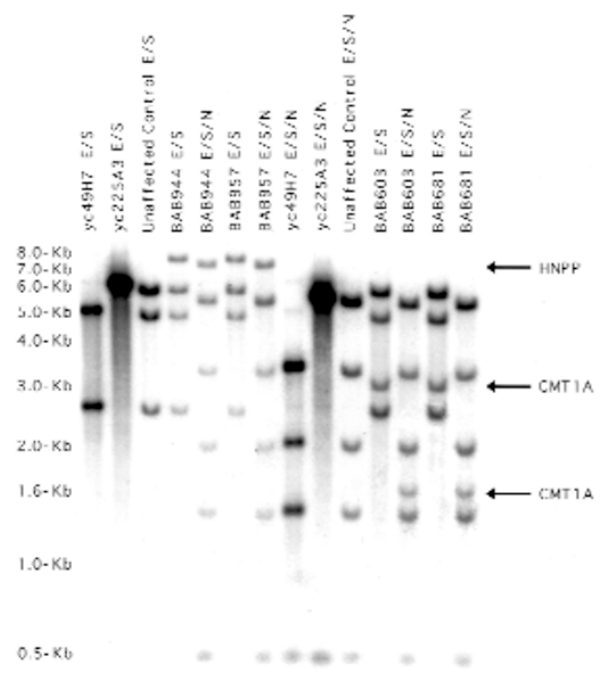

\section{Vertebrate genome evolution and the zebrafish gene map}

John H. Postlethwait, Yi-Lin Yan, Michael A. Gates, Sally Horne, Angel Amores, Alison Brownlie, Adriana Donovan, Elizabeth S. Egan, Allan Force, Zhiyuan Gong, Carole Goutel, Andreas Fritz, Robert Kelsh, Ela Knapik, Eric Liao, Barry Paw, David Ransom, Amy Singer, Margaret Thomson, Tariq S. Abduljabbar, Pam Yelick, Dave Beier, J.-S. Joly, Dan Larhammar, Frederic Rosa, Monte Westerfield, Leonard I. Zon, Steve L. Johnson \& William S. Talbot

Nature Genet. 18, 345-349 (1998).

The name of one of the co-authors, Marc Ekker (Loeb Institute of Medical Research, Ottawa Civic Hospital, 725 Parkdale, Ottawa, Ontario, Canada, K1Y 4E9) was inadvertently omitted from the author list of the manuscript. We apologize for the inconvenience this omission has caused.

\section{Mutations in GDI1 are responsible for X-linked non-specific mental retardation}

Patrizia D’Adamo, Andrea Menegon, Cristiana Lo Nigro, Marina Grasso, Massimo Gulisano, Filippo Tamanini, Thierry Bienvenu, Agi K. Gedeon, Ben Oostra, Shih-Kwang Wu, Anurag Tandon, Flavia Valtorta, William E. Balch, Jamel Chelly \& Daniela Toniolo

Nature Genet. 19, 134-139 (1998).

The common polymorphism detected by SSCP analysis in the GDI gene was erroneously described as A377C. It is, in fact, T377C. 